\section{Conclusion}

Our study identified a level of cylinder usage whereby it becomes cost effective to provide oxygen by concentrator at home in Northern Ireland. A more widespread provision of concentrators is likely to represent a cost saving. We would advocate that regional health authorities review their current arrangements for provision of oxygen at home and perform a cost analysis to determine at what level it becomes more cost effective to provide oxygen by concentrator.

Contributors: LGH had the original idea for the study, retrieved the data, performed the costings, and wrote the paper; he will act as guarantor for the paper. DMcA assisted in performing the costings and contributed to writing the paper

JMacM contributed to data interpretation and writing the paper.

Funding: None

Competing interests: None declared.

1 Medical Research Council Working Party (MRC report). Long term domiciliary oxygen therapy in chronic hypoxic cor pulmonale complicating chronic bronchitis and emphysema. Lancet 1981;i:681-6.

2 Nocturnal Oxygen Therapy Trial Group (NOTT). Continuous or nocturnal oxygen therapy in hypoxaemic chronic obstructive lung disease: a clinical trial. Ann Intern Med 1980;93:391-8.

3 Department of Health. Domiciliary oxygen therapy service. Drug Tariff Part X. London: The Stationery Office, 1996.

Rees PJ. Dudley F. Provision of oxygen at home. BMJ 1998;317:935-8

5 Drummond MF, O' Brien B, Stoddart GL, Torrance GW. Methods for economic evaluation of health care programmes, 2nd ed. Oxford: Oxford Medical, 1997.

(Accepted 26 March 1999)

\title{
Risk of HIV related Kaposi's sarcoma and non-Hodgkin's lymphoma with potent antiretroviral therapy: prospective cohort study
}

\author{
Bruno Ledergerber, Amalio Telenti, Matthias Egger for the Swiss HIV Cohort Study
}

The rate of progression to new AIDS defining events has been reduced considerably since the introduction of potent antiretroviral combination therapy. ${ }^{12}$ It is unclear, however, whether the reduction has been the same for all opportunistic infections and malignancies, or whether the effect has been greater for some conditions than for others. We examined this question in the Swiss HIV Cohort Study, a large community cohort of adults with HIV infection.

\section{Participants, methods, and results}

The study methods are described in detail elsewhere. ${ }^{13}$ The cohort includes the majority of people with advanced HIV infection in Switzerland. Potent antiretroviral combination therapy (triple combinations including at least one protease inhibitor) was gradually introduced from 1995 onwards. By mid-1997, 70\% of patients with a history of CD4 cell counts below $200 \times$ $10^{6} / 1$ were receiving this treatment.

The incidence of all new AIDS conditions fell from 157 events (95\% confidence interval 148 to 166$)$ per 1000 person-years in 1992 to 1994 (before combination therapy) to 35 events (26 to 45 ) in the year from July 1997 to June 1998. We analysed AIDS defining opportunistic and malignant events in separate Cox regression models, treating calendar periods as time dependent covariates and adjusting hazard ratios for transmission group, age, and CD4 cell count at baseline. Analyses were based on 6636 participants and 18498 person-years of follow up.

We found substantial reductions in rates of opportunistic events after the introduction of combination therapy. The figure shows hazard ratios for the common AIDS defining opportunistic infections (50 diagnoses or more), any AIDS defining opportunistic infection (1734 diagnoses), Kaposi's sarcoma (258 diagnoses), and systemic non-Hodgkin's lymphoma (110 diagnoses). The relative hazard for progression to any AIDS defining opportunistic infection was 0.20 (0.15 to 0.27$)$, with little heterogeneity between

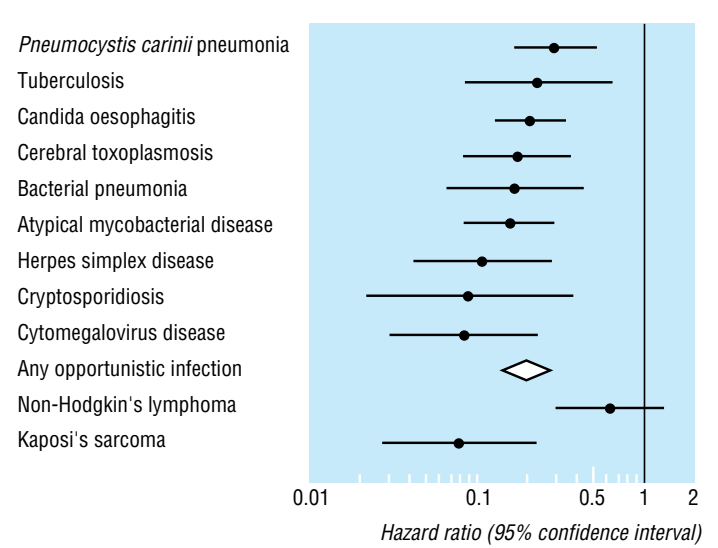

Relative risk (hazard ratio) of AIDS defining opportunistic infections and malignancies, comparing 1992-4 (before introduction of potent antiretroviral combination therapy) with July 1997 to June 1998 (after introduction). Results from Cox regression models adjusted for transmission group, age, and CD4 cell count at baseline

infections. A substantial reduction was also observed for Kaposi's sarcoma (0.08; 0.03 to 0.22). However, no significant trend was evident for non-Hodgkin's lymphoma $(0.61 ; 0.30$ to 1.29$)$, with the difference observed between the two malignancies unlikely to be the product of chance $(\mathrm{P}=0.002)$. Most non-Hodgkin's lymphomas had intermediate or high grade histology and affected extranodal sites. Results for primary lymphoma of the brain were similar to those for nonHodgkin's lymphoma, but the number of cases was small $(n=27)$ and confidence intervals were wide.

\section{Comment}

The incidence of both Kaposi's sarcoma and non-Hodgkin's lymphoma is increased over 100-fold among patients with AIDS, ${ }^{4}$ and these conditions are also more common among patients with other
Division of

Infectious Diseases, Department of

Medicine,

University Hospital Zurich, CH-8091

Zurich, Switzerland Bruno Ledergerber, senior research fellow

Division of

Infectious Diseases,

Department of

Medicine,

University of

Lausanne, $\mathrm{CH}-1011$

Lausanne,

Switzerland

Amalio Telenti,

clinical reader in

infectious diseases

MRC Health

Services Research

Collaboration,

Department of

Social Medicine,

University of

Bristol, Bristol

BS8 2PR

Matthias Egger,

senior lecturer in

epidemiology and

public health medicine

Correspondence to:

Dr Egger

m.egger@bristol.

ac.uk

BMJ 1999;319:23-4

website

extra

Members of the

Swiss HIV Cohort

Study are listed on

the BMJ's website

www.bmj.com 
acquired or congenital immune defects. In addition to immunosuppression, other factors including EpsteinBarr virus infection, chronic antigen stimulation, and proto-oncogenes, have been implicated in the pathogenesis of the different clinical and histopathological manifestations of AIDS related non-Hodgkin's lymphoma, whereas human herpes virus type 8 may be an infectious cofactor which is required for all forms of Kaposi's sarcoma. ${ }^{5}$

Our data indicate that patients cease to be at risk of Kaposi's sarcoma once immune function has been improved by combination therapy. Conversely, patients with a history of severe immunodeficiency continue to be at risk of non-Hodgkin's lymphoma, despite antiretroviral combination therapy. Although the initiation of carcinogenesis requires an immunodeficient state, the factors promoting the development of non-Hodgkin's lymphoma further along the causal chain do not seem to be related to immune function or are related to aspects not affected by antiretroviral combination therapy. Because of the large number of susceptible patients with a history of severe immunodeficiency, the fall in the incidence of non-Hodgkin's lymphoma will probably lag behind that observed for other opportunistic diseases. Non-Hodgkin's lymphoma will thus remain a relatively common complication among patients treated with antiretroviral combination therapy.

We thank the patients for participating.

Contributors: BL initiated the study, performed statistical analyses, and participated in writing the paper. AT discussed core ideas and participated in clinical data collection and writing the paper. ME initiated the study, supervised statistical analyses, and wrote the first draft of the paper. BL and ME are the guarantors for the study.

Funding: Swiss Federal Office of Public Health (Grant No 3600.010.1).

Competing interests: None declared.

1 Egger M, Hirschel B, Francioli P, Sudre P, Wirz M, Flepp M, et al for the Swiss HIV Cohort Study. Impact of new antiretroviral combination therapies in HIV infected patients in Switzerland: prospective therapies in HIV infected patients

2 Mocroft A, Vella S, Benfield TL, Chiesi A, Miller V, Gargalianos P, et al for the EuroSIDA Study Group. Changing patterns of mortality across Europe in patients infected with HIV-1. Lancet 1998;352:1725-30.

3 Ledergerber B, von Overbeck J, Egger M, Lüthy R. The Swiss HIV cohort study: rationale, organization and selected baseline characteristics. Soz Praeventivmed 1994:39:387-94.

4 Goedert JI, Coté TR, Virgo P, Scoppa SM, Kingma DW, Gail MH, et al. Spectrum of AIDS-associated malignant disorders. Lancet 1998:351:1833-9.

5 Chang Y, Cesarman E, Pessin MS, Lee F, Culpepper J, Knowles DM, et al. Identification of herpesvirus-like DNA sequences in AIDS-associated Kaposi's sarcoma. Science 1994;266:1865-9.

(Accepted 19 January 1999)

\title{
Randomised controlled trial of long term efficacy of captopril on preservation of kidney function in normotensive patients with insulin dependent diabetes and microalbuminuria
}

\author{
Elisabeth R Mathiesen, Eva Hommel, Henrik P Hansen, Ulla M Smidt, Hans-Henrik Parving
}

Steno Diabetes

Center, DK 2860

Gentofte,

Copenhagen,

Denmark

Elisabeth R

Mathiesen,

consultant

Eva Hommel,

chief physician

Henrik P Hansen,

research fellow

Ulla M Smidt,

laboratory technician

Hans-Henrik

Parving,

professor

Correspondence to: Dr E R Mathiesen,

Medical Endocrine

Department,

University Hospital

of Copenhagen,

Rigshospitalet, 2100

Copenhagen $\varnothing$,

Denmark

em@rh.dk

BMJ 1999;319:24-5
In patients with insulin dependent diabetes, angiotensin converting enzyme inhibition delays the progression from microalbuminuria to diabetic nephropathy, but previous studies have been too short to show a preservation of kidney function. ${ }^{1-3}$ We assessed the effectiveness of angiotensin converting enzyme inhibition on preservation of kidney function in an 8 year prospective, randomised controlled trial.

\section{Patients, methods, and results}

Forty four normotensive patients with insulin dependent (type I) diabetes and persistent microalbuminuria $(30-300 \mathrm{mg} / 24 \mathrm{~h})$ were enrolled as previously described in detail. ${ }^{1}$ The treatment group $(n=21)$ was given captopril $(100 \mathrm{mg} / 24 \mathrm{~h})$ and bendrofluazide $(2.5 \mathrm{mg} / 24 \mathrm{~h})$. The 23 remaining patients were left untreated. Diabetic nephropathy was defined as albuminuria persistently $>300 \mathrm{mg} / 24 \mathrm{~h}$. Glomerular filtration rate was measured annually with Crom EDTA plasma clearance over 4 hours. ${ }^{1}$

After 4 years two patients in each group were excluded because they did not attend follow up sessions. Four of the patients in the control group started antihypertensive treatment with diuretics, $\beta$ blockers, or a calcium channel blocker. Three patients in the treatment group were changed from bendrofluazide to frusemide because of oedema or diastolic blood pressure $>95 \mathrm{~mm} \mathrm{Hg}$. After 8 years 16 of the 21 patients in the treatment group and two patients from the control group were subsequently investigated after a treatment pause of 2 months.

The proportion of patients who progressed to diabetic nephropathy was $40 \%(9 / 23)$ in the control group and $10 \%(2 / 21)$ in the captopril group (survival analysis $\mathrm{P}=0.019$ ). In the captopril group there was a significant increase in urinary albumin excretion $(\mathrm{P}<0.001)$ during the treatment pause. In six $(38 \%)$ of the 16 patients albuminuria exceeded $300 \mathrm{mg} / 24 \mathrm{~h}$.

Glomerular filtration rate in the captopril group declined from 126 (24) at baseline to $114(23) \mathrm{ml} / \mathrm{min}$ after 8 years but rose again to 126 (21) during the pause in treatment (table). Follow up values of glomerular filtration rate measured during the treatment pause were therefore used whenever available. The decline in mean glomerular filtration rate $(\mathrm{ml} / \mathrm{min})$ was $11.8(95 \%$ confidence interval 1.2 to $22.0 ; t$ test $\mathrm{P}$ value 0.03$)$ and $1.4(-4.9$ to $7.7 ; \mathrm{P}=0.65)$ in the control and captopril group, respectively $(\mathrm{P}=0.09$ between the groups). The fall in glomerular filtration rate during the 8 year study period in the 